\title{
Supporting information: Members of a novel kinase family (DUF1537) can recycle toxic intermediates into an essential metabolite
}

Jennifer J. Thiaville ${ }^{1}$, Jake Flood ${ }^{2}$, Svetlana Yurgel $^{3}$, Laurence Prunetti ${ }^{1}$, Mona Elbadawi-Sidhu ${ }^{4}$, Geoffrey Hutinet ${ }^{1}$, Farhad Forouhar ${ }^{6}$, Xinshuai Zhang ${ }^{7}$, Venkateswaran Ganesan ${ }^{1}$, Patrick Reddy $^{1}$, Oliver Fiehn ${ }^{4,5}$, J. A. Gerlt ${ }^{7}$, John F. Hunt ${ }^{6}$, Shelley D. Copley ${ }^{2}$, and Valérie de Crécy$\operatorname{Lagard}^{1 *}$

${ }^{1}$ Department of Microbiology and Cell Science and Genetic Institute, University of Florida, P.O. Box 110700, Gainesville, FL 32611-0700.

${ }^{2}$ Department of Molecular, Cellular and Developmental Biology, University of Colorado, Boulder, CO, USA

${ }^{3}$ Dalhousie University

${ }^{4}$ West Coast Metabolomics Center, UC Davis, CA

${ }^{5}$ King Abdulaziz University, Biochemistry Department, Jeddah, Saudi-Arabia

${ }^{6}$ Department of Biological Sciences, Columbia University, New York, NY, USA

${ }^{7}$ Institute for Genomic Biology, University of Illinois at Urbana-Champaign, Urbana, Illinois 61801, United States

*To whom correspondence should be addressed.

Valérie de Crécy-Lagard, Department of Microbiology and Cell Science and Genetic Institute, University of Florida, P.O. Box 110700, Gainesville, FL 32611-0700; E-mail : vcrecy@ufl.edu, Tel: (352) 392 9416; Fax: (352) 3925922 


\section{Supplemental Results}

\section{PdxA2 and DUF1537 of $S$. meliloti}

As shown in Figure 2 and 4, S. meliloti encodes three $p d x A$ paralogs and three DUF1537 paralogs. The canonical $p d x A 1$ clusters with $\operatorname{sur} A$ and $k s g A$. The $p d x A 2$ gene (SMb20146) clusters with a DUF1537 gene (SMb20149) and with a putative alcohol dehydrogenase, sialidase, and dihydrodipicolinate synthase. The third $p d x A$ paralog, $p d x A 3(\mathrm{SMb} 20772)$, clusters with tricarboxylate transporters. A previous study demonstrated that $p d x A 2_{S m}$ expression in $B$. subtilis allowed production of pyridoxine in the presence of $p d x J$ of $S$. meliloti or E. coli (1), confirming that the PdxA2 is indeed capable of this activity. A double $p d x A p d x A 2$ or triple $p d x A$ $p d x A 2 p d x A 3$ mutant would likely be needed to produce a PLP auxotroph.

We constructed deletions of the $p d x A 1$ and $p d x A 2$ genes in either WT or the $\Delta p d x R$ strain. Deletion of $p d x A 1$ substantially decreased growth of $S$. meliloti in the absence of pyridoxine (Figure S4). As expected, deletion of $p d x A 2$ alone did not affect growth in the absence of PLP, since the major biosynthetic pathway remained intact in these strains. The double $\triangle p d x R \Delta p d x A 1$ mutant did not grow in the absence of PLP (Figure S4), even with 4HT supplementation, suggesting the activity or expression of the other $p d x A$ paralogs are not high enough in these conditions to allow growth of the double mutant.

The lack of growth of the $p d x R$ mutant of $S$. meliloti in the absence of pyridoxine or $4 \mathrm{HT}$ (Figure S4) is consistent with the results of Tazoe et al. that showed that $p d x R$ is required for PLP synthesis from glycolaldehyde (2). These results also show that in S. meliloti, like in E. coli or $S$. Typhimurium LT2, PLP can be synthesized from 4HT independently of PdxR/PdxB activity. Glycolaldehyde was found to be more toxic in $S$. meliloti than in E. coli or $S$. 
Typhimurium LT2, so the levels of glycoladehyde used (10 nM) might not be sufficient to generate enough 4HT compared to the levels used in the enterobacterial growth (200nM).

\section{Supplemental methods}

Strains and media. Table S1 lists all strains and plasmids used in this study. E. coli and $S$. Typhimurium strains were grown at $37^{\circ} \mathrm{C}$ on LB (Tryptone $10 \mathrm{~g} / \mathrm{L}$, yeast extract $5 \mathrm{~g} / \mathrm{L}, \mathrm{NaCl} 5$ $\mathrm{g} / \mathrm{L})$ or minimal M9 (3) and agar $(0.15 \% \mathrm{w} / \mathrm{v})$ was added for solid media. Glucose $(0.2 \% \mathrm{w} / \mathrm{v})$ or glycerol $(0.2 \% \mathrm{w} / \mathrm{v})$ was added to M9 medium as a carbon source. The following supplements were added to M9 when necessary: pyridoxine $(500 \mathrm{ng} / \mathrm{ml})$, threonine $(40 \mu \mathrm{g} / \mathrm{ml})$, serine $(80$ $\mu \mathrm{g} / \mathrm{ml})$, glycolaldehyde (200 $\mu \mathrm{M})$, 4-hydroxythreonine (100 nM).

S. meliloti was grown on yeast extract-mannitol (YMB) (4) or minimal-mannitol- $\mathrm{NH}_{4}$ (MMNH4) medium (4) at $30^{\circ} \mathrm{C}$. The following supplements were added as necessary: pyridoxine (16 $\mu \mathrm{g} / \mathrm{ml})$, glycolaldehyde (100 $\mu \mathrm{M}$ or $10 \mu \mathrm{M})$, and 4-hydroxythreonine (100 $\mathrm{nM})$.

Construction of mutant strains. Most of the E. coli mutants were obtained from the Keio collection (5). NU812 (E. coli pdxA::kan) was provided by Malcolm Winkler (6). The mutation loci were moved into new strains via P1 transduction (7). The plasmid pCP20 was used to excise the antibiotic resistance cassettes flanked by FRT sites ( 8 ).

S. Typhimurium LT2 mutant strains were constructed by lambda red recombineering (8). PCR Primers were designed with approximately $50 \mathrm{bp}$ of homologous sequence to the gene of interest. P1 and P2 sites (8) were added to each primer to amplify the cat or kan cassettes from pKD3 or pKD4, respectively. For single deletions, $20 \mathrm{ng}$ of PCR product was transformed into $S$. 
Typhimurium LT2 carrying pKD46. Transformants were selected on $20 \mu \mathrm{g} / \mathrm{ml}$ chloramphenicol or $40 \mu \mathrm{g} / \mathrm{ml}$ kanamycin and verified by PCR. VDC9852 (S. Typhimurium LT2 $\Delta p d x A 1:: k a n$ $\Delta p d x A 2:: c a t)$ was constructed by transforming the $\Delta p d x A 1:: k a n$ PCR product into VDC9538 (S. Typhimurium LT2 $\Delta p d x A 2:: c a t$ ) carrying pKD46. Transformants were selected on kanamycin (40 $\mu \mathrm{g} / \mathrm{ml})$ and confirmed to have chloramphenicol resistance. Absence of both the $p d x A l$ and $p d x A 2$ genes and insertion of the antibiotic resistance cassettes were confirmed by PCR.

The S. meliloti deletion mutants were constructed using an insertion/excision strategy (9) with some modifications. Sucrose selection of all mutants was done on YMB plates supplemented with $5 \%$ sucrose and $500 \mathrm{nM}$ pyridoxine. To construct the $S$. meliloti deletion mutants, PCR was used to amplify the two chromosomal regions $(0.5 \mathrm{~kb}$ and $0.6 \mathrm{~kb})$ flanking the regions to be deleted, using primers listed in Table S2. The deletions were confirmed by PCR using primers located outside of the regions flanking those used to construct the deletions and primers located inside of deleted gene. The ability of the strains to grow without pyridoxine was tested after verification of the gene excision.

Cloning for genetic tests. S. Typhimurium LT2 pdxA1 (STM0091), pdxA2 (STM0163), DUF1537 (STM0162) genes were amplified by PCR with primers listed in Table S2 using $S$. Typhimurium LT2 gDNA as a template. The PCR products were digested with restriction enzymes (HindIII and EcoRI for STM0091, HindIII and SalI for STM0162, SmaI for STM0163) and ligated into digested pUC19. For cloning of genes into pBY279.1, the products were bluntend cloned into the SmaI site of pBY279.1. The resulting plasmids are listed in Table S1. Plasmids for complementation of $t h r B, p d x F$, and $p d x B$ mutants with $E$. coli genes were acquired from the ASKA library (10). 
Site-directed Mutagenesis of DUF1537 Site-directed mutagenesis of the $S$. Typhimurium LT2 DUF1537 (STM0162) was performed using the Q5 Site-directed Mutagenesis Kit (NEB). Plasmid pJJT50 was used as the template for PCR with primers listed in Table S2. Following the mutagenesis protocol, the plasmids were transformed into chemical-competent NEB5- $\alpha$ cells and transformants were selected on LB-chloramphenicol. The point mutation resulting in G501A change was confirmed by sequencing, and the plasmid was transformed into VDC9718 for genetic complementation analysis.

Genetic complementation and growth assays. Genetic complementation of mutants was tested by growth on M9 minimal medium with supplements listed in the text with or without pyridoxine. For dilution drops, strains were grown overnight at $37^{\circ} \mathrm{C}$ in $\mathrm{M} 9$ medium with all supplements needed and antibiotic to maintain the plasmid (ampicillin or chloramphenicol). The cultures were washed three times in M9 medium without supplements and normalized to an $\mathrm{OD}_{600}$ of 1 . Ten-fold serial dilutions were made of each strain and $10 \mu \mathrm{l}$ of each dilution were spotted onto M9 agar plate containing supplements indicated in text.

For Bioscreen growth curves, strains were grown overnight at $37^{\circ} \mathrm{C}$ or $30^{\circ} \mathrm{C}$ in appropriate media (M9 for E. coli and $S$. Typhimurium LT2 and $\mathrm{MMNH}_{4}$ for $S$. meliloti) with all supplements as needed and antibiotic selection for the plasmid (ampicillin or chloramphenicol). The cultures were washed three times in the same medium without supplements and normalized to an $\mathrm{OD}_{600}$ of 0.1 . The strains were diluted in a Bioscreen plate to a final $\mathrm{OD}_{600}$ of 0.005 in appropriate medium with supplements as indicated in the text. Growth curves were performed on a Bioscreen $\mathrm{C}$ machine (Growth Curves USA, Piscataway, $\mathrm{NJ}$ ) with shaking incubation at $37^{\circ} \mathrm{C}$ 
(for E. coli and S. Typhimurium LT2) or $30^{\circ} \mathrm{C}$ (for S. meliloti). All growth curves are the average of three biological replicates.

Purification of recombinant proteins. The gene encoding DUF1537 (STM0162) and $p d x A 2$ (STM0163) of $S$. Typhimurium LT2 were amplified by PCR using the primers FW DUF1537, and RV DUF1537, and FW PdxA2 and RV PdxA2, respectively (Table S2), and cloned between the NdeI and BlpI sites of pET28a (+), which adds an N-terminal hexa-histidine tag. Sequenceverified constructs were transformed into E. coli strain Rosetta-Gami 2(DE3) via chemical transformation. For protein purification, transformants were grown at $37^{\circ} \mathrm{C}$ in $\mathrm{LB}$ medium with kanamycin $(50 \mu \mathrm{g} / \mathrm{ml})$ until $\mathrm{OD}_{600}$ reached approximately 0.4 , at which time isopropyl $\beta$-d-1thiogalactopyranoside (IPTG) was added to a final concentration of $0.4 \mathrm{mM}$. After $4 \mathrm{~h}$ at $25^{\circ} \mathrm{C}$, cells were harvested by centrifugation and stored at $-80^{\circ} \mathrm{C}$.

Cell pellets were resuspended in buffer A $(50 \mathrm{mM}$ Tris- $\mathrm{HCl}, 5 \%$ glycerol, $300 \mathrm{mM} \mathrm{NaCl}, \mathrm{pH}$ 7.5) supplemented with $40 \mathrm{mM}$ imidazole, $\mathrm{pH} 7.5$ (4 ml per $1 \mathrm{~g}$ wet weight) and lysed thrice by passage through a French Press cell (2000 psi). Cell lysate was clarified by centrifugation (twice for $20 \mathrm{~min}$ at $17,000 \times g$ at $\left.4^{\circ} \mathrm{C}\right)$ and filtration $(0.8 \mu \mathrm{M}$ cellulose acetate membrane, Fisher Scientific). The proteins were applied to a HisTrap HP column (5 ml, GE Healthcare) preequilibrated in buffer A supplemented with $40 \mathrm{mM}$ imidazole and washed with the same buffer. The proteins were eluted using buffer A supplemented with $500 \mathrm{mM}$ imidazole. The eluate was concentrated to a volume final of $500 \mu 1$ using a Vivaspin centrifugal concentrator $(10,000$ molecular weight cut off membrane) and applied to a Superdex 200 HR 10/30 gel filtration column (FPLC, GE Healthcare) equilibrated with buffer A at a flow of $0.3 \mathrm{ml} \cdot \mathrm{min}^{-1}$. Fractions were collected every $0.5 \mathrm{ml}$. Molecular mass was determined using a Superdex 200 10/30 
column (Pharmacia). Mixed gel filtration standards (Gel filtration standard, Biorad) were used to calibrate the column.

LtaE and ThrB were each expressed with an N-terminal His-tag from pET45b in E. coli BL21 (DE3) and were purified by nickel affinity chromatography, as previously described (11).

Protein concentration. Protein concentrations were determined by the bicinchoninic acid method (12) (Thermo Scientific Pierce BCA Protein Assay Kit, Rockford, IL) with bovine serum albumin as the protein standard.

Electrophoresis. Protein samples were mixed in equal volume ratio with $2 \mathrm{X}$ loading buffer [containing $125 \mathrm{mM}$ Tris-HCl, $\mathrm{pH}$ 6.8, $20 \mathrm{mM} \beta$-mercaptoethanol, 4\% (w/v) SDS, 20\% (v/v) glycerol and $0.01 \%(\mathrm{w} / \mathrm{v})$ bromophenol blue] and boiled for $10 \mathrm{~min}$. Samples were separated by 10\% SDS-PAGE (reducing gels) using a mini-Protean III cell electrophoresis apparatus (Bio$\mathrm{Rad})$ at $20 \mathrm{~mA}$ at room temperature in a running buffer of $25 \mathrm{mM}$ Tris- $\mathrm{HCl}$ and $190 \mathrm{mM}$ glycine at $\mathrm{pH} 8.3$ with $0.1 \%(\mathrm{w} / \mathrm{v})$ SDS. After migration, proteins were stained in-gel with Coomassie Blue R-250.

\section{Activity Measurements}

ATP binding. Thermal denaturation of DUF1537 STM0162 from $S$. Typhimurium LT2 was monitored using a fluorescent reporter dye (13). Protein $(10 \mu \mathrm{M})$ was mixed with SYPRO Orange dye (Invitrogen, Carlsbad, CA, 5x final concentration) and the indicated additives in a buffer containing $150 \mathrm{mM} \mathrm{NaCl}, 100 \mathrm{mM}$ HEPES, $\mathrm{pH} 7.5$. Thermal titrations of the protein were conducted in the presence of $5 \mathrm{mM} \mathrm{Mg}-\mathrm{ATP}-\gamma-\mathrm{S}$. Thermal titrations of the-protein were conducted in the presence and absence of $5 \mathrm{mM} \mathrm{MgCl}_{2}$. Fluorescence at $590 \mathrm{~nm}$ was monitored using $492 \mathrm{~nm}$ excitation in a Mx3005P Real-Time PCR system (Stratagene) as the temperature 
was raised by $1{ }^{\circ} \mathrm{C}$ per min. The fluorescence level at each temperature was plotted relative to baselines extrapolated from the pre- and post-transition regions using linear least-squares regressions.

Assay of PdxA2 activity. PdxA2 activity was measured by following the reduction of $\mathrm{NAD}^{+}$at $340 \mathrm{~nm}$ at $25^{\circ} \mathrm{C}$. The reaction mixture contained $1 \mathrm{mM} \mathrm{NAD}^{+}$, varying levels of $4 \mathrm{PHT}, 319 \mathrm{nM}$ $\mathrm{PdxA} 2$, and $50 \mathrm{mM} \mathrm{NaCl}$ in $50 \mathrm{mM}$ Tris- $\mathrm{HCl}$, $\mathrm{pH} 8.0$.

Assay of DUF1537 kinase activity. DUF1537 kinase activity was measured in a coupled assay system in which ADP formed by phosphorylation of the substrate (4HT or D-threonate) was converted to ATP by pyruvate kinase, and pyruvate formed by conversion of PEP to pyruvate by pyruvate kinase was converted to lactate by pyruvate dehydrogenase. Reduction of pyruvate was followed by monitoring the decrease in the absorbance of NADH at $340 \mathrm{~nm}$ with a Cary 300 Bio UV-Visible spectrophotometer (Varian). The reaction mixture $\left(25^{\circ} \mathrm{C}\right)$ contained variable concentrations of substrate, $100 \mathrm{mM}$ Tris- $\mathrm{HCl}$ buffer $\mathrm{pH} 8.0,10 \mathrm{mM} \mathrm{KCl}, 10 \mathrm{mM} \mathrm{MgCl} 2,2.5$ mM ATP, $2.5 \mathrm{mM}$ PEP, $0.16 \mathrm{mM}$ NADH, 5 units pyruvate kinase/lactate dehydrogenase from rabbit muscle (Sigma) and enzyme in a final volume of $200 \mu \mathrm{L}$. Data were fit to the MichaelisMenten equation.

Coupled DUF1537 kinase/PdxA reaction. To confirm that DUF1537 phosphorylates 4HT at the 4' position, a coupled assay was performed to determine whether the product could be oxidized by PdxA. A reaction mixture containing $2 \mathrm{mM}$ ATP, $200 \mu \mathrm{M}$ 4HT, $2.74 \mu \mathrm{M}$ STM0162, $50 \mathrm{mM}$ $\mathrm{NaCl}$ and $10 \mathrm{mM}$ magnesium acetate in $50 \mathrm{mM}$ Tris- $\mathrm{HCl}, \mathrm{pH} 8.0$, was incubated at $25^{\circ} \mathrm{C}$ for 2 hours. The progress of the reaction was monitored in a parallel reaction containing pyruvate kinase, lactate dehydrogenase, ATP and NADH as described above. After 2 hours, 2 mM NAD ${ }^{+}$ 
and $1.45 \mu \mathrm{M}$ E. coli PdxA were added. PdxA-dependent reduction of $\mathrm{NAD}^{+}$demonstrated that 4HT kinase had phosphorylated 4HT at the 4' position.

\section{Detection of 4HT and 4PHT by mass spectrometry}

Preparation of Samples. Six independent cultures of VDC9814 (E. coli $\Delta p d x B \Delta t h r B p d x A:: k a n$ carrying either pJJT50 (pBY279.1::STM0163) or pBY279.1 (empty vector) were grown overnight with shaking at $37^{\circ} \mathrm{C}$ overnight in $\mathrm{M} 9$ minimal medium containing $0.4 \%$ glucose, 500 $\mathrm{nM}$ pyridoxine, $40 \mu \mathrm{g} / \mathrm{ml}$ threonine, and $25 \mu \mathrm{g} / \mathrm{ml}$ chloramphenicol. The following day, cultures were diluted to an $\mathrm{OD}_{600}$ of 0.05 in fresh M9 medium containing all supplements plus $200 \mu \mathrm{M}$ glycolaldehyde and $500 \mathrm{ng} / \mathrm{ml}$ anhydrotetracycline. The strains were grown until the $\mathrm{OD}_{600}$ reached 1.0. One $\mathrm{ml}$ of each culture was pelleted at $16,000 \mathrm{x} \mathrm{g}$ for 30 seconds, the supernatants were removed, and the pellets were flash frozen in liquid nitrogen and stored at $-80^{\circ} \mathrm{C}$.

Detection of $4 H T$ and $4 P H T$ in samples. Samples were extracted by adding $1 \mathrm{ml}$ of $3: 1$ methanol:water to each sample tube and vortexing for $20 \mathrm{sec}$ followed by sonication for $5 \mathrm{~min}$. Protein precipitation was facilitated by incubating the samples at $-20^{\circ} \mathrm{C}$ for $30 \mathrm{~min}$, followed by centrifugation for $2 \mathrm{~min}$ at $14,000 \mathrm{xg}$. A $475 \mu \mathrm{l}$ aliquot of the resulting supernatant from each sample tube was transferred to a separate $1.5 \mathrm{ml}$ Eppendorf tube and dried with a LabConco FreeZone lyophilizer (LabConco Corporation, Kansas City, MO) overnight. The dried material was resuspended in $60 \mu 1$ of 1:1 acetonitrile:water and centrifuged for 2 min at 14,000 x g prior

to transfer into amber glass LC vials. Chromatography was performed on an Agilent 1290 Infinity LC System (Agilent Technologies, Santa Clara, CA). Samples were maintained at $4{ }^{\circ} \mathrm{C}$ in the autosampler and $5 \mu 1$ of sample material was injected onto an Imtakt Scherzo SM-C18 150 x $2.0 \mathrm{~mm}$ HPLC column kept at $30{ }^{\circ} \mathrm{C}$. Mobile phase A consisted of $0.1 \%$ formic acid in $\mathrm{H}_{2} \mathrm{O}$ 
and mobile phase B consisted of $0.1 \%$ formic acid in acetonitrile. Target metabolites were eluted from the column using the following gradient: 0 to $5 \mathrm{~min}-0 \% \mathrm{~B}, 5.01$ to $6 \mathrm{~min}-$ linear gradient to $15 \% \mathrm{~B}, 6$ to $7 \mathrm{~min}$ - linear gradient to $90 \% \mathrm{~B}$, hold for $1 \mathrm{~min}, 8$ to $8.5 \mathrm{~min}$ - linear gradient to $0 \% \mathrm{~B}$, hold for $3.5 \mathrm{~min}$. Flow rate was held at $0.3 \mathrm{ml} / \mathrm{min}$ throughout the method. Metabolites were detected with an Agilent 6550 accurate-mass quadrupole time-of-flight (Q-TOF) mass spectrometer equipped with a Dual Agilent Jet Stream ESI source. Data were acquired in positive ionization mode from $\mathrm{m} / \mathrm{z} 60-500$ with a 4 spectra/second scan rate. Target analytes were identified based on retention time and accurate mass matching to authentic standards for 4HT and 4PHT, described below.

Chemicals. L-serine was obtained from Research Products International and Sigma-Aldrich. All other chemicals and reagents were obtained Sigma-Aldrich, unless otherwise stated. Pyruvate kinase and Lactate dehydrogenase were obtained from Sigma-Aldrich. L-4-hydroxythreonine (4HT) was chemically synthesized as previously described (14) or enzymatically synthesized as previously described (15). L-4-phosphohydroxythreonine (4PHT) was enzymatically synthesized from glycolaldehyde, glycine, and ATP by enzymatic methods using threonine aldolase (LtaE) and homoserine kinase (ThrB). The biosynthetic reaction contained $100 \mathrm{mM}$ HEPES (pH 7.4), $100 \mathrm{mM} \mathrm{MgSO}$, $300 \mathrm{mM} \mathrm{KCl,} 50 \mathrm{mM}$ glycine, $50 \mathrm{mM}$ glycolaldehyde (dimer), $10 \mathrm{mM} \mathrm{ATP,}$ $16 \mu \mathrm{M} \mathrm{LtaE}$, and $22 \mu \mathrm{M} \mathrm{ThrB}$ and was incubated at $25^{\circ} \mathrm{C}$ for $3 \mathrm{~h}$. Proteins were removed using Amicon ultrafiltration (30K cut-off). The reaction mixture was diluted to $500 \mathrm{ml}$ with ice-cold water and was loaded onto a $20 \mathrm{ml}$ Sephadex A-25 column using a peristaltic pump at $4{ }^{\circ} \mathrm{C}$. The column was washed with $500 \mathrm{ml}$ of $20 \mathrm{mM}$ triethylammonium bicarbonate (TEAB) buffer (pH 7.5) and the 4PHT was eluted using $80 \mathrm{ml}$ of $200 \mathrm{mM}$ TEAB (pH 7.5). The TEAB was removed 
using a Rotovap. The yield of 4PHT ( $25 \%)$ was evaluated by enzymatic formation of NADPH using 4-hydroxy-L-threonine dehydrogenase (PdxA) in the presence of $100 \mu \mathrm{M} \mathrm{NAD}^{+}$.

\section{References}

1. Commichau, F. M., Alzinger, A., Sande, R., Bretzel, W., Reuss, D. R., Dormeyer, M., Chevreux, B., Schuldes, J., Daniel, R., Akeroyd, M., Wyss, M., Hohmann, H. P., and Pragai, Z. (2015) Engineering Bacillus subtilis for the conversion of the antimetabolite 4hydroxy-1-threonine to pyridoxine, Metab Eng 29, 196-207.

2. Tazoe, M., Ichikawa, K., and Hoshino, T. (2006) Flavin adenine dinucleotide-dependent 4-phospho-D-erythronate dehydrogenase is responsible for the 4-phosphohydroxy-Lthreonine pathway in vitamin B6 biosynthesis in Sinorhizobium meliloti, J Bacteriol 188, $4635-4645$.

3. Sambrook, J. E., Fritsch, F., and Maniatis, T. (1989) Molecular cloning : A laboratory manual, 2nd edn., Cold Spring Harbor Laboratory Press, Cold Spring Harbor.

4. Somerville, J. E., and Kahn, M. L. (1983) Cloning of the glutamine synthetase I gene from Rhizobium meliloti, J Bacteriol 156, 168-176.

5. Baba, T., Ara, T., Hasegawa, M., Takai, Y., Okumura, Y., Baba, M., Datsenko, K. A., Tomita, M., Wanner, B. L., and Mori, H. (2006) Construction of Escherichia coli K-12 in-frame, single-gene knockout mutants: the Keio collection, Mol Syst Biol 2, 20060008.

6. Roa, B. B., Connolly, D. M., and Winkler, M. E. (1989) Overlap between $p d x A$ and $k s g A$ in the complex pdxA-ksgA-apaG-apaH operon of Escherichia coli K-12, J. Bacteriol 171, 4767-4777. 
7. Moore, S. D. (2011) Assembling new Escherichia coli strains by transduction using phage P1, Methods Mol Biol 765, 155-169.

8. Datsenko, K. A., and Wanner, B. L. (2000) One-step inactivation of chromosomal genes in Escherichia coli K-12 using PCR products, Proc Natl Acad Sci U S A 97, 6640-6645.

9. Yurgel, S. N., Berrocal, J., Wilson, C., and Kahn, M. L. (2007) Pleiotropic effects of mutations that alter the Sinorhizobium meliloti cytochrome c respiratory system, Microbiology 153, 399-410.

10. Kitagawa, M., Ara, T., Arifuzzaman, M., Ioka-Nakamichi, T., Inamoto, E., Toyonaga, H., and Mori, H. (2005) Complete set of ORF clones of Escherichia coli ASKA library (a complete set of E. coli $\mathrm{K}-12 \mathrm{ORF}$ archive): unique resources for biological research, DNA Res 12, 291-299.

11. Kim, J., Kershner, J. P., Novikov, Y., Shoemaker, R. K., and Copley, S. D. (2010) Three serendipitous pathways in E. coli can bypass a block in pyridoxal-5'-phosphate synthesis, Mol Syst Biol 6, 436.

12. Smith, P. K., Krohn, R. I., Hermanson, G. T., Mallia, A. K., Gartner, F. H., Provenzano, M. D., Fujimoto, E. K., Goeke, N. M., Olson, B. J., and Klenk, D. C. (1985) Measurement of protein using bicinchoninic acid, Anal Biochem 150, 76-85.

13. Pantoliano, M. W., Petrella, E. C., Kwasnoski, J. D., Lobanov, V. S., Myslik, J., Graf, E., Carver, T., Asel, E., Springer, B. A., Lane, P., and Salemme, F. R. (2001) High-density miniaturized thermal shift assays as a general strategy for drug discovery, $J$ Biomol Screen 6, 429-440.

14. Wolf, E., and Spenser, I. D. (1995) [2,3-13C2]-4-Hydroxy-L-threonine, J Org Chem 60, 6937-6940. 
15. Cativiela, C., Día-de-Villegas, M. D., Gálvez, J., and García, J. (1996) Diastereoselective Strecker reaction of D-glyceraldehyde derivatives. A novel route to $(2 \mathrm{~S}, 3 \mathrm{~S})$ - and $(2 \mathrm{R}, 3 \mathrm{~S})$ 2-amino-3,4-dihydroxybutyric acid, Tetrahedron 52, 9563-9574. 
Table S1. List of strains and plasmids used in this study.

\begin{tabular}{|c|c|c|}
\hline Strain, plasmid & Phenotype, genotype and/or description ${ }^{\mathrm{a}}$ & Ref/Source \\
\hline \multicolumn{3}{|c|}{ - } \\
\hline BW25113 & $\begin{array}{l}\text { F- }, \Delta(\operatorname{araD}-a r a B) 567, \Delta l a c Z 4787(: \because r r n B-3), \lambda-, r p h-1, \\
\Delta(r h a D-r h a B) 568, h s d R 514\end{array}$ & EGSC \\
\hline NU426 & W3110; F-, $\lambda-$, IN(rrnD-rrnE) 1, rph-1 & $\begin{array}{l}\text { C. Yanofsky } \\
\text { collection }\end{array}$ \\
\hline \multirow[t]{2}{*}{ GC10 } & F- $m c r A \Delta(m r r-h s d R \mathrm{MS}-m c r B C) \phi 80 \mathrm{~d} l a c Z \Delta \mathrm{M} 15$ & \multirow[t]{2}{*}{ Gene Choice } \\
\hline & $\begin{array}{l}\Delta l a c X 74 \text { endA1 recA1 } \Delta(\text { ara, leu }) 7697 \text { araD139 galU } \\
\text { galK nup G rpsL } \lambda \text { - T1R; } \operatorname{Str}^{R}\end{array}$ & \\
\hline Rosetta-gami2 (DE3) & 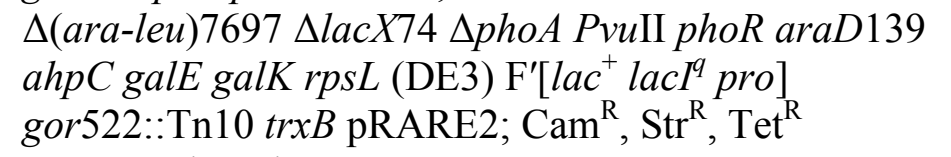 & Novagen \\
\hline NU812 & W3110 pdxA::kan & (29) \\
\hline JW0002 & BW25113 $\Delta t h r B:: k a n$ & (55) \\
\hline JW2317 & BW25113 $\Delta p d x B: \operatorname{kan}$ & (55) \\
\hline JW2548 & BW25113 $\Delta p d x J::$ kan & (55) \\
\hline JW1628 & BW25113 $\Delta p d x Y:: k a n$ & (55) \\
\hline JW1630 & BW25113 $\Delta p d x H::$ kan & (55) \\
\hline JW0890 & BW25113 $\Delta \operatorname{ser} C(p d x F)::$ kan & (55) \\
\hline VDC9706 & $\begin{array}{l}\text { BW25113 } \Delta p d x B ; \text { JW2317 with } \operatorname{kan}^{\mathrm{R}} \text { cassette removed } \\
\text { by FLP-catalyzed excision using pCP } 20\end{array}$ & This study \\
\hline VDC9718 & $\begin{array}{l}\text { BW25113 } \Delta p d x B \Delta t h r B:: k a n ; \Delta t h r B:: \text { kan }^{\mathrm{R}} \text { transduced } \\
\text { via P1 from JW0002 intoVDC9607; }{ }^{\mathrm{R}}\end{array}$ & This study \\
\hline VDC9769 & $\begin{array}{l}\text { BW25113 } \Delta p d x B \Delta t h r B ; \text { VDC } 9718 \text { with } \operatorname{Kan}^{\mathrm{R}} \text { cassette } \\
\text { removed by FLP-catalyzed excision using pCP } 20\end{array}$ & This study \\
\hline VDC9778 & $\begin{array}{l}\mathrm{BW} 25113 \Delta p d x B \Delta \text { thrB } \Delta \text { ltaE::kan; } \Delta t h r B:: \mathrm{kan} \\
\text { transduced via P1 from JW0002 intoVDC9607; Kan }\end{array}$ & This study \\
\hline VDC9810 & $\begin{array}{l}\text { BW25113 pdxA::kan; BW25113 transduced with P1 } \\
\text { lysate from NU812; Kan }{ }^{\mathrm{R}}\end{array}$ & This study \\
\hline VDC9812 & $\begin{array}{l}\text { BW25113 } \Delta p d x B p d x A:: k a n ; \text { VDC9706 transduced } \\
\text { with P1 lysate from NU812; Kan }{ }^{R}\end{array}$ & This study \\
\hline VDC9814 & $\begin{array}{l}\mathrm{BW} 25113 \Delta p d x B \Delta t h r B p d x A:: \mathrm{kan} ; \mathrm{VDC} 9769 \\
\text { transduced with P1 lysate from NU812 }\end{array}$ & This study \\
\hline VDC9816 & $\begin{array}{l}\text { BW25113 } \Delta p d x B \Delta p d x J:: k a n ; \text { VDC9706 transduced } \\
\text { with P1 lysate from JW2548; Kan }{ }^{R}\end{array}$ & This study \\
\hline VDC9818 & $\begin{array}{l}\text { BW25113 } \Delta p d x B \Delta t h r B \Delta p d x J:: k a n ; \mathrm{VDC} 9769 \\
\text { transduced with P1 lysate from JW2548; Kan }\end{array}$ & This study \\
\hline VDC9822 & $\begin{array}{l}\text { BW25113 } \Delta p d x B \Delta t h r B \Delta p d x H:: k a n ; \mathrm{VDC} 9769 \\
\text { transduced with P1 lysate from JW1630; Kan }{ }^{\mathrm{R}}\end{array}$ & This study \\
\hline VDC9858 & $\begin{array}{l}\text { BW25113 } \Delta p d x B \Delta t h r B \Delta \operatorname{ser} C(p d x F):: k a n ; \mathrm{VDC} 9769 \\
\text { transduced with P1 lysate from JW0890; Kan }{ }^{\mathrm{R}}\end{array}$ & This study \\
\hline \multicolumn{3}{|c|}{ Salmonella Typhimurium } \\
\hline LT2 & $\begin{array}{l}\text { Salmonella enterica serovar Typhimurium LT2; wild- } \\
\text { type }\end{array}$ & (64) \\
\hline
\end{tabular}




\begin{tabular}{|c|c|c|}
\hline Strain, plasmid & Phenotype, genotype and/or description ${ }^{\mathrm{a}}$ & Ref/Source \\
\hline VDC9536 & LT2 $\Delta p d x A::$ kan & This study \\
\hline VDC9538 & LT2 $\triangle p d x A 2:: c a t$ & This study \\
\hline VDC9852 & LT2 $\Delta p d x A::$ kan $\Delta p d x A 2:: c a t$ & This study \\
\hline \multicolumn{3}{|c|}{ Sinorhizobium meliloti } \\
\hline SM1021 & S. meliloti SM1021 Wild-type & S. Yurgel \\
\hline $\mathrm{SM} 1021 \Delta p d x R$ & S. meliloti SM1021 $\Delta p d x R$ & This study \\
\hline $\operatorname{SM} 1021 \Delta p d x A 1$ & S. meliloti SM1021 $\Delta p d x A 1$ & This study \\
\hline $\mathrm{SM} 1021 \Delta p d x A 2$ & S. meliloti SM1021 $\Delta p d x A 2$ & This study \\
\hline SM1021 $\Delta$ DUF1537 & S. meliloti SM1021 $\Delta$ DUF1537 & This study \\
\hline $\mathrm{SM} 1021 \Delta p d x R$ & S. meliloti SM1021 $\Delta p d x R \Delta p d x A 1$ & This study \\
\hline $\begin{array}{l}\Delta p d x A 1 \\
\operatorname{SM} 1021 \Delta p d x R \\
\Delta p d x A 2\end{array}$ & S. meliloti SM1021 $\Delta p d x R \Delta p d x A 2$ & This study \\
\hline $\begin{array}{l}\mathrm{SM} 1021 \Delta p d x R \\
\Delta D U F 1537\end{array}$ & S. meliloti SM1021 $\Delta p d x R \Delta$ DUF1537 & This study \\
\hline $\begin{array}{l}\text { Plasmids } \\
\text { pUC19 } \\
\text { pBY279.1 }\end{array}$ & $\begin{array}{l}\mathrm{Amp}^{\mathrm{R}} ; \text { LacZ cloning vector; } \mathrm{pBR} 322 \text { ori } \\
\mathrm{Cam}^{\mathrm{R}}, \mathrm{Kan}^{\mathrm{R}} ; \mathrm{P}_{\mathrm{TET}} \text { expression vector; } \mathrm{p} 15 \mathrm{~A} \text { ori }\end{array}$ & $\begin{array}{l}(65) \\
(33)\end{array}$ \\
\hline $\begin{array}{l}\text { pNU244 } \\
\text { pVG01 }\end{array}$ & $\begin{array}{l}\mathrm{Amp}^{\mathrm{R}} ; p d x A \text { of } E \text {. coli cloned into } \mathrm{pBR} 322 \text { vector } \\
\mathrm{Amp} \mathrm{p}^{\mathrm{R}} \mathrm{STM} 0091(p d x A) \text { of } S \text {. Typhimurium LT2 cloned } \\
\text { into pUC19 }\end{array}$ & $\begin{array}{l}(29) \\
\text { This study }\end{array}$ \\
\hline pVG05 & $\begin{array}{l}\left.\mathrm{Cam}^{\mathrm{R}}, \mathrm{Kan}^{\mathrm{R}} \text {; STM0091 ( } p d x A\right) \text { of } S \text {. Typhimurium LT2 } \\
\text { cloned pBY279.1; under control of } \mathrm{P}_{\mathrm{TET}}\end{array}$ & This study \\
\hline pJJT37 & $\begin{array}{l}\text { Cam }^{\mathrm{R}}, \text { Kan }^{\mathrm{R}} ; \text { STM0163 }(p d x A 2) \text { of } S \text {. Typhimurium } \\
\text { LT2 cloned pBY279.1; under control of } \mathrm{P}_{\mathrm{TET}}\end{array}$ & This study \\
\hline pJJT47 & $\begin{array}{l}\text { Amp }{ }^{\mathrm{R}} \text {; STM0162 (DUF1537) of } S \text {. Typhimurium LT2 } \\
\text { cloned of pUC19 }\end{array}$ & This study \\
\hline pJJT48 & $\begin{array}{l}\text { Amp }^{\mathrm{R}} ; \text { STM0163 (pdxA2) of } S . \text { Typhimurium LT2 } \\
\text { cloned of pUC19 }\end{array}$ & This study \\
\hline pJJT50 & $\begin{array}{l}\mathrm{Cam}^{\mathrm{R}}, \mathrm{Kan}^{\mathrm{R}} \text {; STM0162 (DUF1537) of } S \text {. Typhmurium } \\
\text { LT2 cloned into pBY279.1; under control of } \mathrm{P}_{\mathrm{TET}}\end{array}$ & This study \\
\hline pJJT57 & $\begin{array}{l}\mathrm{Amp}^{\mathrm{R}} ; y g b K \text { of } E \text {. coli } \mathrm{MG} 1655 \text { cloned into } \\
E c o \mathrm{RI} / X b a \mathrm{I} \text { sites of } \mathrm{pUC} 18\end{array}$ & This study \\
\hline pJJT79 & $\begin{array}{l}\text { Cam }^{\mathrm{R}}, \operatorname{Kan}^{\mathrm{R}} ; \text { pdxA2-linked DUF1537 (Asuc_0446) } \\
\text { from Actinobacillus succinogenes } 130 \mathrm{Z} \text { cloned into } \\
\text { SmaI/SalI of pBY279.1; under control of } \mathrm{P}_{\mathrm{TET}}\end{array}$ & This study \\
\hline pJJT80 & $\begin{array}{l}\text { Cam }^{\mathrm{R}}, \text { Kan }^{\mathrm{R}} ; \text { pdxA2-linked DUF1537 (Asuc_0446) } \\
\text { from Actinobacillus succinogenes } 130 \mathrm{Z} \text { cloned into } \\
\text { SmaI/Sall of pBY279.1; under control of } \mathrm{P}_{\mathrm{TET}}\end{array}$ & This study \\
\hline pJJT81 & $\begin{array}{l}\mathrm{Cam}^{\mathrm{R}}, \mathrm{Kan}^{\mathrm{R}} \text {; RUBISCO-like-linked DUF1537 } \\
(\text { Aaur_1904)) from Arthrobacter aurescens } \mathrm{TC} 1 \text { cloned } \\
\text { into SmaI/SalI of pBY279.1; under control of } \mathrm{P}_{\mathrm{TET}}\end{array}$ & This study \\
\hline pJJT82 & $\begin{array}{l}\text { Cam }^{\mathrm{R}}, \text { Kan }^{\mathrm{R}} ; \text { DUF } 1537 \text { (Npun_F3646) from Nostoc } \\
\text { punctiforme PCC73102 cloned into SmaI/SalI of }\end{array}$ & This study \\
\hline
\end{tabular}




\begin{tabular}{|c|c|c|}
\hline Strain, plasmid & Phenotype, genotype and/or description ${ }^{\mathrm{a}}$ & Ref/Source \\
\hline pJJT83 & $\begin{array}{l}\text { pBY279.1; under control of } \mathrm{P}_{\mathrm{TET}} \\
\text { Cam }^{\mathrm{R}}, \text { Kan }^{\mathrm{R}} ; \text { pdxA2-linked DUF1537 ( ECA3761) from } \\
\text { Pectobacterium atrosepticum SCRI1403 cloned into }\end{array}$ & This study \\
\hline pJJT84 & 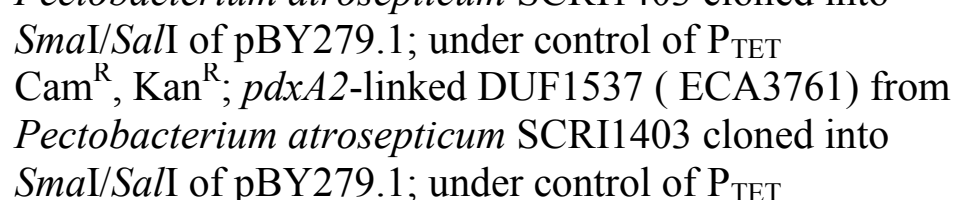 & This study \\
\hline pJJT85 & $\begin{array}{l}\mathrm{Cam}^{\mathrm{R}}, \mathrm{Kan}^{\mathrm{R}} ; \text { pdxA2-linked DUF1537 from } \\
\text { Mannheimia haemolytica } \text { PHL213 cloned into } \\
\text { SmaI/SalI of pBY279.1; under control of } \mathrm{P}_{\mathrm{TET}}\end{array}$ & This study \\
\hline pJJT130 & $\begin{array}{l}\text { Cam }^{\mathrm{R}} \text {, Kan }{ }^{\mathrm{R}} \text {; DUF1537 (Pro1753) of Prochlorococcus } \\
\text { marinus subsp. marinus str. CCMP1375 cloned into } \\
\text { SmaI/SalI of pBY279.1; under control of } \mathrm{P}_{\mathrm{TET}}\end{array}$ & This study \\
\hline pJJT162 & $\begin{array}{l}\text { Cam }{ }^{\mathrm{R}} ; p d x A 2 \text {-linked DUF1537 (SMb20149) cloned } \\
\text { into pBAD33; under control of } \mathrm{P}_{\mathrm{BAD}}\end{array}$ & This study \\
\hline pJJT163 & $\begin{array}{l}\text { Cam }^{\mathrm{R}} \text {; RLP-linked DUF1537 (SMb20394) cloned into } \\
\text { pBAD33; under control of } \mathrm{P}_{\mathrm{BAD}}\end{array}$ & This study \\
\hline pJJT190 & $\begin{array}{l}\mathrm{Cam}^{\mathrm{R}}, \mathrm{Kan}^{\mathrm{R}} \text {; Site-directed mutagenesis of pJJT50 to } \\
\text { give DUF1537 G401A }\end{array}$ & This study \\
\hline pCA24N:: thrB & $\begin{array}{l}\text { Cam }^{\mathrm{R}} \text {; Clone expressing E. coli thrB acquired from } \\
\text { ASKA collection }\end{array}$ & $\begin{array}{l}\text { ASKA } \\
\text { collection; } \\
(59)\end{array}$ \\
\hline pCA24N::pdxB & $\begin{array}{l}\text { Cam }^{\mathrm{R}} \text { : Clone expressing } E \text {. coli } p d x B \text { acquired from } \\
\text { ASKA collection }\end{array}$ & $\begin{array}{l}\text { ASKA } \\
\text { collection; } \\
\text { (59) }\end{array}$ \\
\hline pKD46 & $\begin{array}{l}\mathrm{Amp}^{\mathrm{R}} \text {; Plasmid for } \lambda \text { Red; Arabinose-inducible } \\
\text { expression of exo, bet, gam; Temperature sensitive } \\
\text { replication (repA101ts) }\end{array}$ & $(57)$ \\
\hline pKD3 & $\mathrm{Amp}^{\mathrm{R}}, \mathrm{Cam}^{\mathrm{R}}$; Plasmid for amplification of cat cassette & (57) \\
\hline pKD4 & $\mathrm{Amp}^{\mathrm{R}}, \mathrm{Kan}^{\mathrm{R}}$; Plasmid for amplification of kan cassette & (57) \\
\hline $\mathrm{pCP} 20$ & $\begin{array}{l}\mathrm{Amp}^{\mathrm{R}}, \mathrm{Cam}^{\mathrm{R}} ; \text { Plasmid for induction of FLP } \\
\text { recombinase }\end{array}$ & (66) \\
\hline pET28a & $\mathrm{Cm}^{\mathrm{r}}, \mathrm{Kan}^{\mathrm{r}}$; expression vector for $E$. coli (DE3) strains & Novagen \\
\hline pET28::STM0163 & $\mathrm{Cm}^{\mathrm{r}}, \mathrm{Kan}^{\mathrm{r}} ;$ His-STM0163 cloned in pET28a & This study \\
\hline pET28::STM0162 & $\mathrm{Cm}^{\mathrm{r}}, \mathrm{Kan}^{\mathrm{r}} ;$ His-STM0162 cloned in pET28a & This study \\
\hline
\end{tabular}

${ }^{a}$ Abbreviations: $\mathrm{Cam}^{\mathrm{r}}$, chloramphenicol resistance; $\operatorname{Kan}^{\mathrm{r}}$, kanamycin resistance; $\operatorname{Str}^{\mathrm{R}}$, streptomycine resistance; $\mathrm{Tet}^{\mathrm{R}}$, tetracycline resistance; $\mathrm{Amp}^{\mathrm{R}}$, ampicillin resistance; His-, Nterminal poly-His 6 tag fusion protein. 
Table S2. Oligonucleotides used in this study

\begin{tabular}{|c|c|}
\hline Oligo Name & Oligonucleotide sequence (5' to 3') \\
\hline STM0091_del_5 & $\begin{array}{l}\text { AAGCGTTTACGGGCTAAATGGCCCTGATGGACTCGATTA } \\
\text { TTCATATGAATATCCTCCTTA }\end{array}$ \\
\hline STM0091_del_3 & $\begin{array}{l}\text { ACAGCGCGCCAGCGCTTACGTTAAGATTTTGAGTAACTA } \\
\text { AGTGTAGGCTGGAGCTGCTTC }\end{array}$ \\
\hline STM0163_del_5 & $\begin{array}{l}\text { ACGTTGTGTGACGCGCTTTATTATATTGAGGAGATGTATT } \\
\text { GTGTAGGCTGGAGCTGCTTC }\end{array}$ \\
\hline STM0163_del_3 & $\begin{array}{l}\text { TTCAGATACGCCACAATGAGATCCAGACGGTGTTGTCCT } \\
\text { TTCATATGAATATCCTCCTTA }\end{array}$ \\
\hline STM0091 Ext-up & GATCGCGGTCAAGTTCAATGAC \\
\hline STM0091 ext-down & GATCGAATTGCTGGATACGCG \\
\hline STM0091 int_3 & GGCCGAGCGTAATATTCACTC \\
\hline STM0091 int 5 & GTCGTCCAACTGGCGCAACG \\
\hline STM0163 ext 5.2 & CGTTAAACATTATCGAGCAGG \\
\hline STM0163 ext 3 & GATCAAATCGCGACGGATAGTG \\
\hline STM0163 Int -5 & CGAAGACGGTCTCAACGGCG \\
\hline STM0163-Int 3 & CCATGATCAGCAGAGGTCCG \\
\hline EcpdxA_out_dn & GATGCAGGAACAACGTGCCAG \\
\hline EcpdxA_out_up & GAGATGTTATAAGGCAGGTTG \\
\hline EcpdxA_in_F & GCAAACTGCGGGCACATTAAC \\
\hline EcpdxA_in_R & GCTGAAACAGGGTATCGGCAG \\
\hline Kan1 & GCGTTGCCAATGATGTTACAG \\
\hline Kan2 & CCGAGGCAGTTCCATAGGATG \\
\hline LT2 PdxA1 5' HindIII & CTAAGCTTCCAGCGCTTACGTTAAGATTTTG \\
\hline LT2 PdxA1 3' EcoR1 & CTGAATTCCTCGATTATTCATTGGGTATTAAC \\
\hline LT2 PdxA2 5' HindIII & CTAAGCTTGTGACGCGCTTTATTATATTGAG \\
\hline LT2 PdxA2 3' EcoR1 & CTGAATTCGGGAATTATGCCAGTTGCATTG \\
\hline STM0162_5_HindIII.SmaI & CGTGA $\underline{A A G C T T C C C G G G C T T C T T T G G A G A A A A A C G C A T G ~}$ \\
\hline STM0162_3_SalI & GATCGAGTCGACGGTTTTAGTCTCCACAATACATC \\
\hline STM0163_3_HindIII.SalI & GATCGAAGCTTGTCGACACAGGGAATTATGCCAGTTGC \\
\hline STM0163_5_SmaI & CGTGAACCCGGGTTGAGGAGATGTATTGTGGAGAC \\
\hline EcygbK_5-SDEcoRI.KpnI & $\begin{array}{l}\text { CAGTAGGTACCAGGAGGATTCACCATGATCAAGATTGGC } \\
\text { GTTATC }\end{array}$ \\
\hline EcygbK_3-XbaI & GTACGTCTAGACAGTGCGTTTACCCACGG \\
\hline LT2-pdxA1-3'-EcoRI & CT GAATTC CTCGATTATTCATTGGGTATTAAC \\
\hline LT2-pdxA1-5'-HindIII & CT AAGCTT CCAGCGCTTACGTTAAGATTTTG \\
\hline Ec-LtaE-out-up & CGCCCATGCTGTGCACCAG \\
\hline
\end{tabular}




\begin{tabular}{ll}
\hline Oligo Name & Oligonucleotide sequence (5' to 3') \\
\hline Ec-LtaE-out-down & CGTGTAGAAAAAGCGTCTGAAG \\
Ec-LtaE-in5 & GGTTGGGGACGACGTTACG \\
Ec-LtaE-in3 & CAGTTGTTCGCGCGAGACGTC \\
Ec-pdxB-out-down & CCACAGTTCTGCTCTTTGCTG \\
Ec-pdxB-out-up & CAGTCGAATTCAGCGGCATC \\
Ec-pdxB-in-5 & CCGTTTGGGTGAGGTGACC \\
Ec-pdxB-in-3 & CAGAGATGACCATTCACGGC \\
Ec-thrB-out-up & CAACTCGACGATCTCTTTGCC \\
Ec-thrB-out-down & CTTTCAACATTGGCGACCGGAG \\
Ec-thrB-in-5 & CGGTGACACCTGTTGATGG \\
Ec-thrB-in-3 & GTAGTTCTTACCCAACCAGTC \\
serC-in-5 & GAGTTCATTCAGGTTGCAGAGG \\
serC-in-3 & CAATTTGTCAAGCGCACTGTCC \\
serC-out-5 & GTTGTAGTGAAATCATTCATATG \\
serC-out-3 & CGATCGGCTGAAAGCGTATAGC \\
Ec-pdxJ-out-up & GCTTCGCCAGAAAACGCAC \\
Ec-pdxJ-out-down & GAATTTCCTGACGCAGACACAC \\
Ec-pdxJ-in-5 & GGCGGGAGCGGACGGCATTAC \\
Ec-pdxJ-in3 & CTGCCACCGCATCTTTCAGTC \\
Ec-pdxY-out-up & GCATACGCGGTGAAACTGAATC \\
Ec-pdxY-out-down & GGTGAAAAACAGTCCGATCCTG \\
Ec-pdxY-in-5 & GGTAACAGTGCGGCAGAGTTTC \\
Ec-pdxY-in3 & GGCAATACGATCCTGAGCAGC \\
Ec-pdxK-out-up & GAGAAAGCCAAGTCTACCCTG \\
Ec-pdxK-out-down & CATTAGTAGTGTAATGACCAGAC \\
Ec-pdxK-in-5 & GTTTACGGCAGCGTGGGCAAC \\
Ec-pdxK-in3 & GCAAGCCACTGATGAGCTGAG \\
Ec-pdxY-out-up & GCATACGCGGTGAAACTGAATC \\
pBAD-F & CGCAACTCTCTACTGTTTCTCC \\
pBAD-R & GTATCAGGCTGAAAATCTTCTC \\
Ptet_F & CGTCTTCACCTCGAGTCCC \\
pSGC-F & GATCCCGGGTGTAGATCTGGGTACCGAG \\
pSGC-R & CAAGCTTGTCGACGGAGCTCGAATTCGGATCC \\
STM0162-G401A-F & ACCAAAGCGGcCGGATTCGGT \\
STM0162-G401A-R & AATGACCGGCAGATCGTC \\
FW PdxA2 & CGGCATCATATGGAGACTAAAACCGTTGC \\
\hline &
\end{tabular}




\begin{tabular}{ll}
\hline Oligo Name & Oligonucleotide sequence (5' to 3') \\
\hline RV PdxA2 & TTAAGCCAGTTGCATTGCCAGTT \\
FW DUF1537 & CGGCATCATATGAAAATGATAGTTATCGCC \\
RV DUF1537 & AATAACGCTCAGCTTAGTCTCCACAATACA \\
\hline
\end{tabular}

Restriction endonuclease sequences underlined. 
Table S3. UniProt IDs for sequences used to generate trees in Figures 2 and 4

\begin{tabular}{|c|c|c|c|}
\hline UniProt ID & Locus & Gene Context & Organism \\
\hline A6VPQ5 & Asuc_1598 & $\begin{array}{l}\text { PdxA2-linked } \\
\text { DUF1537 } \\
\text { PdxA2-linked }\end{array}$ & Actinobacillus succinogenes $130 \mathrm{Z}$ \\
\hline Q65EJ4 & BL03433 & $\begin{array}{l}\text { DUF1537 } \\
\text { PdxA2-linked }\end{array}$ & Bacillus licheniformis ATCC 14580 \\
\hline A0A0H3KUF6 & BMULJ_05425 & $\begin{array}{l}\text { DUF1537 } \\
\text { PdxA2-linked }\end{array}$ & Burkholderia multivorans ATCC 17616 \\
\hline A0A0W3CXY2 ${ }^{a}$ & AL530_19820 & $\begin{array}{l}\text { DUF1537 } \\
\text { PdxA2-linked }\end{array}$ & $\begin{array}{l}\text { Escherichia coli KTE87 } \\
\text { Lactobacillus paracasei subsp. paracasei }\end{array}$ \\
\hline C5F752 & LBPG_01298 & $\begin{array}{l}\text { DUF1537 } \\
\text { PdxA2-linked }\end{array}$ & $8700: 2$ \\
\hline Q6D0N7 & ECA3761 & $\begin{array}{l}\text { DUF1537 } \\
\text { PdxA2-linked }\end{array}$ & Pectobacterium atrosepticum SCRI1043 \\
\hline Q6AB11 & PPA0298 & $\begin{array}{l}\text { DUF1537 } \\
\text { PdxA2-linked }\end{array}$ & Propionibacterium acnes KPA171202 \\
\hline Q8ZRS5 & STM0162 & $\begin{array}{l}\text { DUF1537 } \\
\text { PdxA2-linked }\end{array}$ & Salmonella Typhimurium LT2 \\
\hline C9LXC3 & Selsp_0545 & $\begin{array}{l}\text { DUF1537 } \\
\text { PdxA2-linked }\end{array}$ & Selenomonas sputigena ATCC 35185 \\
\hline Q92X13 & SM_b20149 & $\begin{array}{l}\text { DUF1537 } \\
\text { RLP-linked }\end{array}$ & Sinorhizobium meliloti 1021 \\
\hline A1R5Z0 & AAur_1904 & $\begin{array}{l}\text { DUF1537 } \\
\text { RLP-linked }\end{array}$ & Arthrobacter aurescens TC1 \\
\hline Q1YDM8 & SI859A1_00100 & $\begin{array}{l}\text { DUF1537 } \\
\text { RLP-linked }\end{array}$ & Aurantimonas manganoxydans SI85-9A1 \\
\hline Q5WAJ7 & ABC4082 & $\begin{array}{l}\text { DUF1537 } \\
\text { RLP-linked }\end{array}$ & Bacillus clausii KSM-K16 \\
\hline A0A0H3LIQ0 & BB1034 & $\begin{array}{l}\text { DUF1537 } \\
\text { RLP-linked }\end{array}$ & Bordetella bronchiseptica RB50 \\
\hline B8IBH5 & Mnod_2419 & $\begin{array}{l}\text { DUF1537 } \\
\text { RLP-linked }\end{array}$ & Methylobacterium nodulans ORS 2060 \\
\hline Q92WF9 & SM_b20394 & $\begin{array}{l}\text { DUF1537 } \\
\text { YgbK-like }\end{array}$ & Sinorhizobium meliloti 1021 \\
\hline Q63KE4 & $\begin{array}{l}\text { BPSS1416 } \\
\text { HMPREF9406 }\end{array}$ & $\begin{array}{l}\text { DUF1537 } \\
\text { YgbK-like }\end{array}$ & Burkholderia pseudomallei 1655 \\
\hline E4LWP3 & 3662 & $\begin{array}{l}\text { DUF1537 } \\
\text { YgbK-like }\end{array}$ & Clostridium sp. HGF2 \\
\hline Q46889 & b2737 & $\begin{array}{l}\text { DUF1537 } \\
\text { YgbK-like }\end{array}$ & Escherichia coli MG1655 \\
\hline B8IEE9 & Mnod_4654 & $\begin{array}{l}\text { DUF1537 } \\
\text { YgbK-like }\end{array}$ & Methylobacterium nodulans ORS 2060 \\
\hline Q6CZ25 & ECA4328 & $\begin{array}{l}\text { DUF1537 } \\
\text { YgbK-like }\end{array}$ & Pectobacterium atrosepticum SCRI1043 \\
\hline Q8ZMG5 & $\begin{array}{l}\text { STM2917 } \\
\text { HMPREF0758_ }\end{array}$ & $\begin{array}{l}\text { DUF1537 } \\
\text { YgbK-like }\end{array}$ & Salmonella Typhimurium LT2 \\
\hline D4E8Z5 & 4645 & $\begin{array}{l}\text { DUF1537 } \\
\text { YgbK-like }\end{array}$ & Serratia odorifera DSM 4582 \\
\hline Q92TW7 & SM_b20670 & DUF1537 & Sinorhizobium meliloti 1021 \\
\hline
\end{tabular}




\begin{tabular}{|c|c|c|c|}
\hline UniProt ID & Locus & Gene Context & Organism \\
\hline D0WWR8 & VMC_16180 & $\begin{array}{l}\text { YgbK-like } \\
\text { DUF1537 } \\
\text { YgbK-like }\end{array}$ & Vibrio alginolyticus $40 \mathrm{~B}$ \\
\hline F0LYZ8 & vfu_B00946 & DUF1537 & Vibrio furnissii NCTC 11218 \\
\hline B2J2W9 & Npun_F3646 & DUF1537 & Nostoc punctiforme PCC73102 \\
\hline Q7V9S4 & Pro_1753 & DUF1537 & Prochlorococcus marinus CCMP1375 \\
\hline A6VPP4 & Asuc_1587 & PdxA & Actinobacillus succinogenes $130 \mathrm{Z}$ \\
\hline A0A0H3LM25 & BB1921 & PdxA & Bordetella bronchiseptica RB50 \\
\hline Q63X77 & BPSL0660 & PdxA & Burkholderia pseudomallei K96243 \\
\hline Q4HSN6 & $\begin{array}{l}\text { CUP0350 } \\
\text { CtesDRAFT_PD }\end{array}$ & PdxA & Campylobacter upsaliensis RM3195 \\
\hline B7WV03 & 4326 & PdxA & Comamonas testosteroni KF-1 \\
\hline A9BX58 & Daci_5505 & PdxA & Delftia acidovorans SPH-1 \\
\hline P19624 & b0052 & PdxA & Escherichia coli MG1655 \\
\hline D0K1S0 & HPKB_1505 & PdxA & Helicobacter pylori \\
\hline A0A022T1I5 & LIMLP_03350 & PdxA & Leptospira interrogans sv. Manilae \\
\hline B2J8Q4 & Npun_F4164 & PdxA & Nostoc punctiforme PCC73102 \\
\hline B1ZQS3 & Oter_4553 & PdxA & Opitutus terrae PB90-1 \\
\hline Q6D0E1 & ECA3858 & PdxA & Pectobacterium atrosepticum SCRI1043 \\
\hline Q7VEI5 & Pro_0028 & pdxA & Prochlorococcus marinus CCMP1375 \\
\hline P58717 & STM0091 & PdxA & Salmonella Typhimurium LT2 \\
\hline Q92QZ0 & SMc00580 & PdxA & Sinorhizobium meliloti 1021 \\
\hline D7BYL9 & SBI_00426 & PdxA & Streptomyces bingchenggensis BCW-1 \\
\hline Q7MP85 & VV0479 & PdxA & Vibrio vulnificus YJ016 \\
\hline B8HE59 & Achl_1102 & PdxA-like & Arthrobacter chlorophenolicus A6 \\
\hline Q65EJ5 & BL03434 & PdxA-like & Bacillus licheniformis ATCC 14580 \\
\hline A0A0H3LQK8 & BB3214 & PdxA-like & Bordetella bronchiseptica RB50 \\
\hline A0A0H2XR18 & Bcen_1534 & PdxA-like & Burkholderia cenocepacia AU1054 \\
\hline A5I3X9 & СBO2208 & PdxA-like & Clostridium botulinum A \\
\hline A6WG90 & Krad_4366 & PdxA-like & Kineococcus radiotolerans SRS30216 \\
\hline B5XQV5 & KPK_2749 & PdxA-like & Klebsiella pneumoniae 342 \\
\hline A0A0D6UG86 & HW40_02925 & PdxA-like & Mannheimia haemolytica PHL213 \\
\hline B1ZNR3 & Oter_2150 & PdxA-like & Opitutus terrae PB90-1 \\
\hline Q6D0N8 & ECA3760 & PdxA-like & Pectobacterium atrosepticum SCRI1043 \\
\hline A0A0U3BU41 & ALW21_01530 & PdxA-like & Propionibacterium acnes \\
\hline P58718 & STM0163 & PdxA-like & Salmonella Typhimurium LT2 \\
\hline Q92X16 & SMb20146 & PdxA-like & Sinorhizobium meliloti 1021 \\
\hline D1CHU7 & Tter_2423 & PdxA-like & Thermobaculum terrenum ATCC BAA-798 \\
\hline A6VPQ6 & Asuc_1599 & PdxA-like 1 & Actinobacillus succinogenes $130 \mathrm{Z}$ \\
\hline A6VQQ4 & Asuc_1953 & PdxA-like 2 & Actinobacillus succinogenes $130 \mathrm{Z}$ \\
\hline B5XMU1 & KPK_3432 & PdxA-like 2 & Klebsiella pneumoniae 342 \\
\hline Q92TP3 & SMb20772 & PdxA-like 3 & Sinorhizobium meliloti 1021 \\
\hline
\end{tabular}

${ }^{\mathrm{a}}$ Sequence not present in UniProt. UniProt ID given for protein with identical sequence from Escherichia fergusonii 


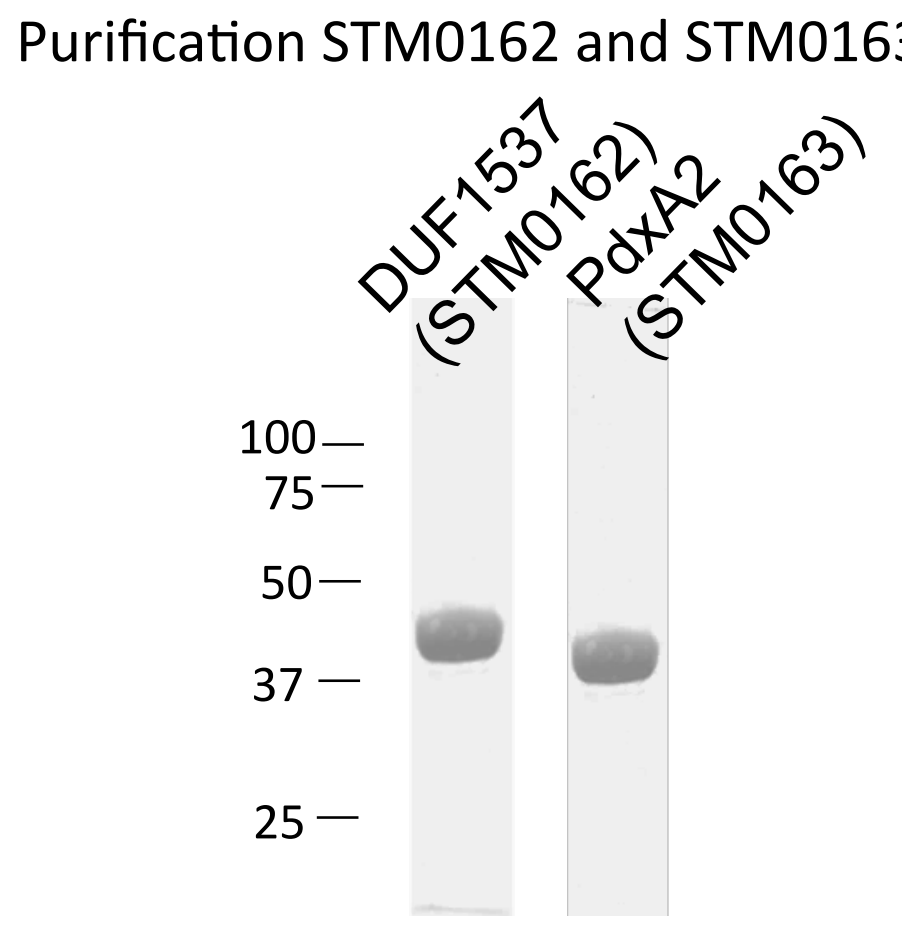

Figure S1. SDS-PAGE of purified PdxA2 and DUF1537

Ten mg of purified DUF1537 (STM0162) and PdxA2 (STM0163) were loaded on a $10 \%$ SDS-PAGE gel. Masses of molecular mass markers are indicated on the left in $\mathrm{kDa}$. The proteins were detected by Coomassie Blue staining. 


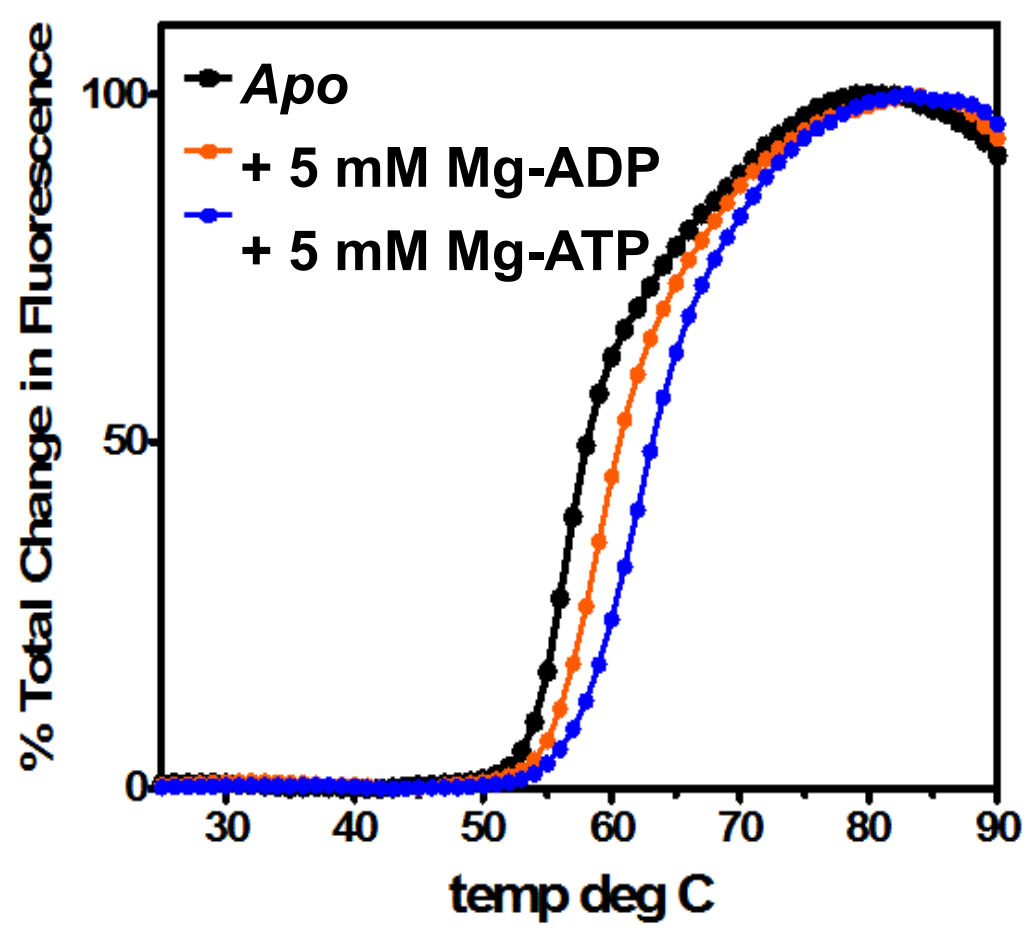

Figure S2. Thermal shift of DUF1537 binding ATP

Thermal denaturation of DUF1537 protein from S. Typhimurium was monitored by measuring fluorescence at $590 \mathrm{~nm}$ with $492 \mathrm{~nm}$ excitation as the temperature was raised $1{ }^{\circ} \mathrm{C}$ per min. Ten $\mu \mathrm{M}$ of the protein was mixed with SYPRO Orange dye and titrated in the presence of $5 \mathrm{mM} \mathrm{Mg-ATP-} \gamma-S, 5 \mathrm{mM} \mathrm{Mg-ADP}$, or $5 \mathrm{mM} \mathrm{MgCl}_{2}($ Apo $)$. 
4-phosphohydroxythreonine

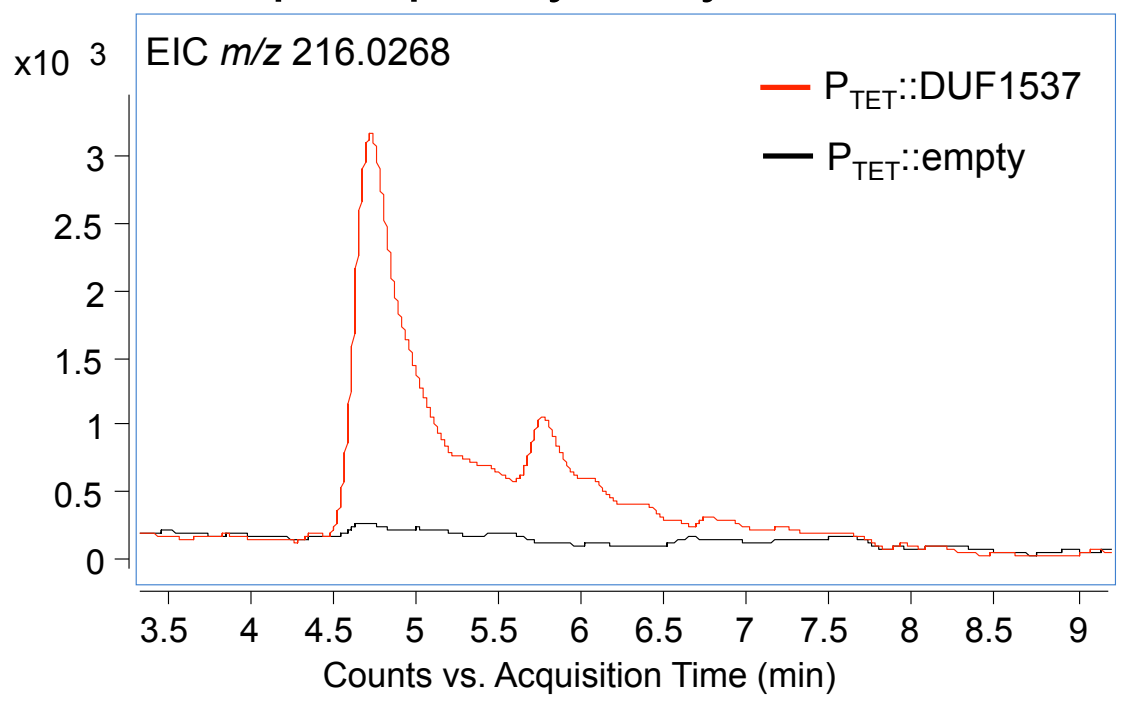

4-hydroxythreonine

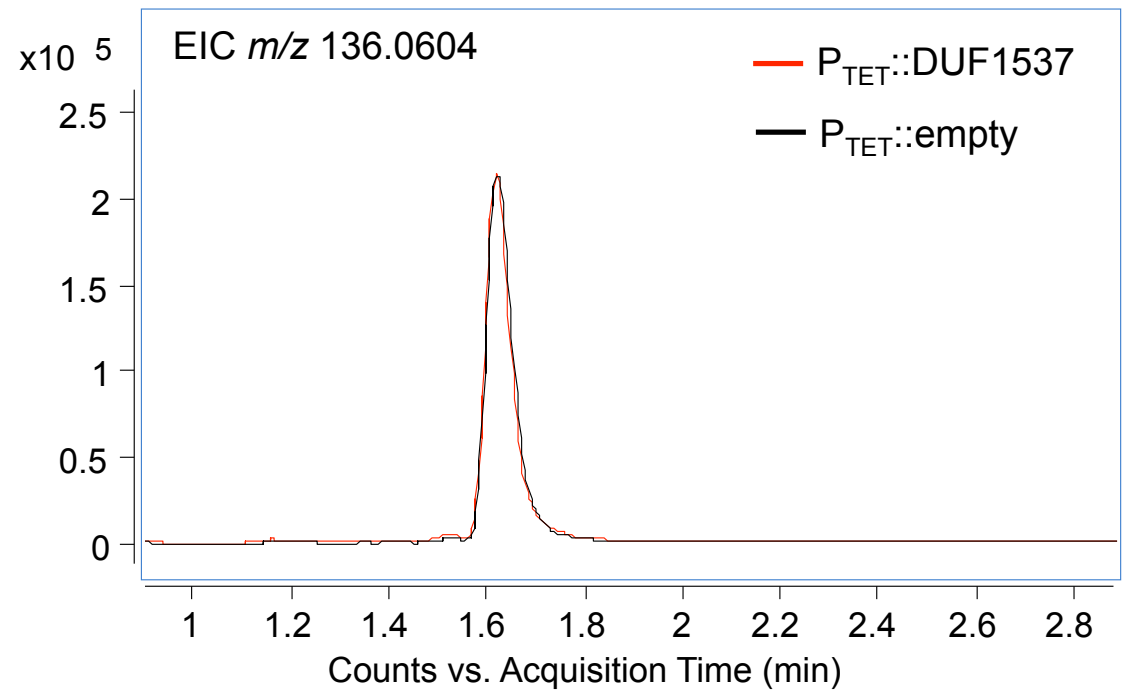

Figure S3. M/S chromatogram of $4 \mathrm{PHT}$ and $4 \mathrm{HT}$ from cell extracts of E. coli $\Delta p d x B \Delta t h r B p d x A$ ::kan expressing DUF1537 $\left(\mathrm{P}_{\mathrm{TET}}:: \mathrm{DUF1537)}\right.$ or not $\left(\mathrm{P}_{\mathrm{TET}}::\right.$ empty). Strains were grown to an $\mathrm{OD}_{600}$ of 1 in $\mathrm{M9}$ medium with chloramphenicol, anhydrotetracycline, pyridoxine, threonine, and glycolaldehyde. Six biological replicates of each were analyzed by $\mathrm{M} / \mathrm{S}$ as described in methods. Chromatogram shown is one representative sample. 


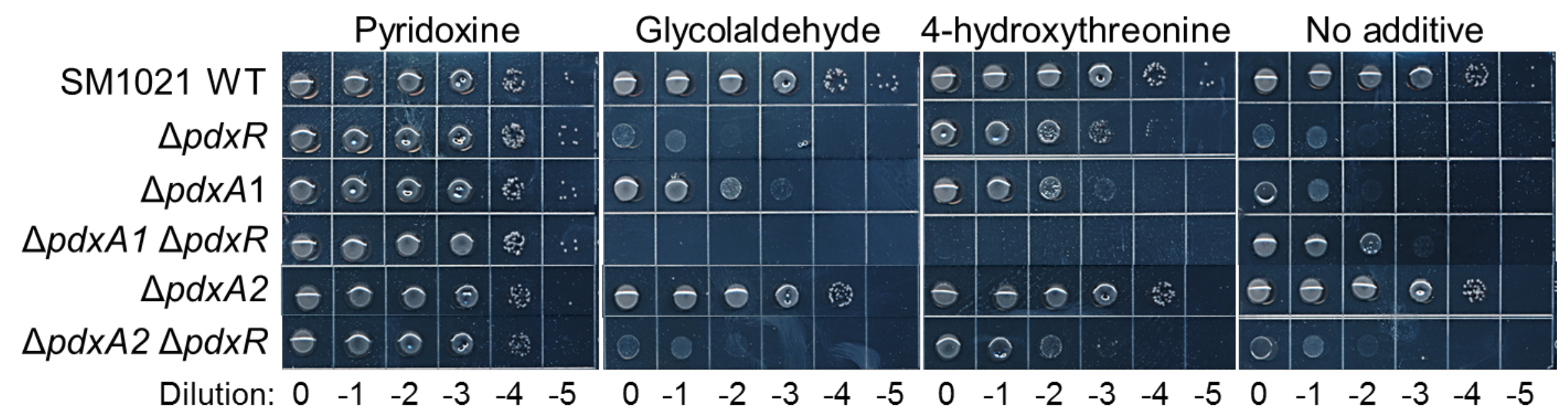

Figure S4. Phenotypes of $S$. meliloti $\triangle p d x R, \Delta p d x A 1$ and $\triangle p d x A 2$ derivatives. Ten $\mu \mathrm{l}$ of 10 -fold serial dilutions of $S$. meliloti mutant strains were spotted onto $\mathrm{MMNH}_{4}$ agar supplemented with either pyridoxine, glycolaldehyde, 4-hydroxythreonine, or no additive and incubated at $30^{\circ} \mathrm{C}$ for $48 \mathrm{~h}$. 
DUF1537 clustering with $p d x A$-like gene

Salmonella Typhimurium str. LT2

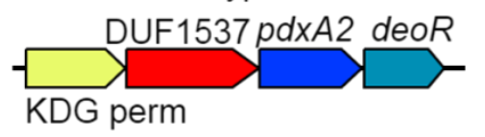

Actinobacillus succinogenes $130 \mathrm{Z}$

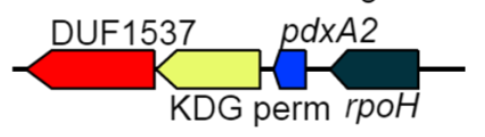

Mannheimia haemolytica PHL213

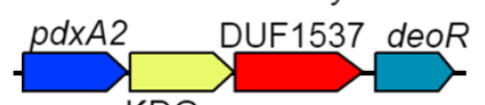

KDG perm

Sinorhizobium meliloti 1021

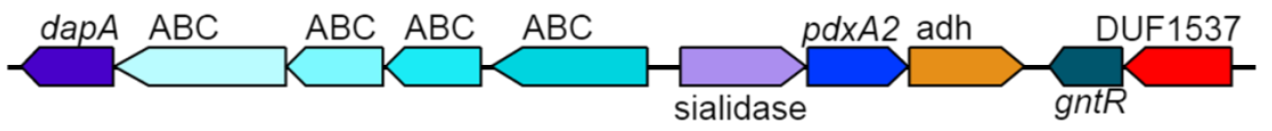

Pectobacterium atrosepticum SCRI1043

$A B C A B C A B C$ deoR pdxA2 DUF1537

\section{YgbK-like DUF1537}

Salmonella Typhimurium LT2

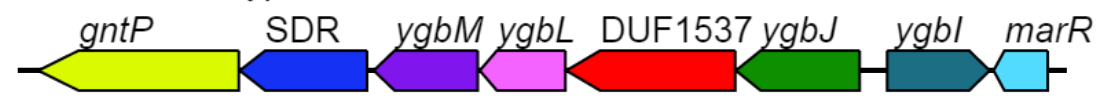

Sinorhizobium meliloti 1021

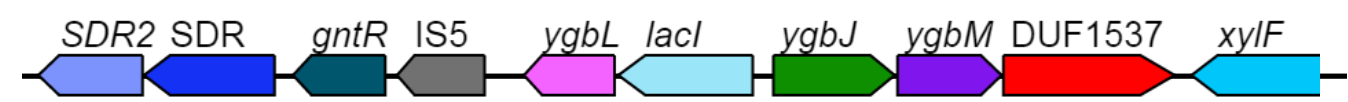

\section{DUF1537 clustering with RLP gene}

Sinorhizobium meliloti 1021

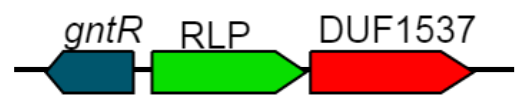

Arthrobacter aurescens TC1

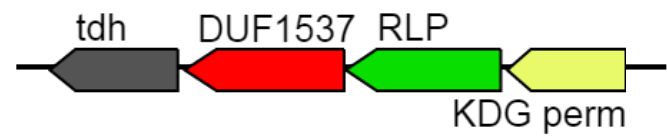

\section{DUF1537 with unique clusters}

Prochlorococcus marinus subsp. marinus str. CCMP1375

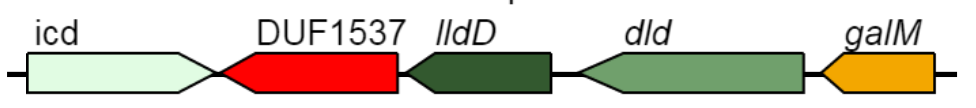

Nostoc punctiforme PCC 73102

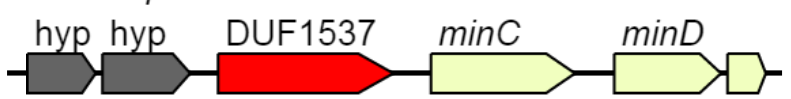

Escherichia coli str. K-12 substr. MG1655 ygbl ygbJ DUF1537 ygbL ygbM ygbN
Figure S5: Gene clusters of DUF1537 genes tested for complementation of PLP auxotrophy of $E$. coli $\Delta p d x B \Delta t h r B:$ :kan (see table 3 for results). 